\title{
Schistosomiasis with Cervical Cancer: About 2 Cases and Literature Review
}

\author{
Nomenjanahary Lalaina ${ }^{1}$, Raivoherivony Zo Irène ${ }^{1}$, M. Ramarokoto Malalafinaritra Patrick ${ }^{2}$, \\ Randaoharison Pierana Gabriël ${ }^{3}$, Randrianjafisamindrakotroka Nantenaina Soa ${ }^{4}$
}

${ }^{1}$ Department of Pathology, Joseph Ravoahangy Andrianavalona University Hospital, Antananarivo, Madagascar

${ }^{2}$ Department of Obstetrics and Gynaecology, Androva University Hospital, Mahajanga, Madagascar

${ }^{3}$ Department of Obstetrics and Gynaecology, Medical School of Mahajanga, Mahajanga, Madagascar

${ }^{4}$ Department of Pathology, Medical School of Antananarivo, Antananarivo, Madagascar

Email: ireneraivoherivony@gmail.com

How to cite this paper: Lalaina, N., Irène, R.Z., Patrick, M.R.M., Gabriël, R.P. and Soa, R.N. (2021) Schistosomiasis with Cervical Cancer: About 2 Cases and Literature Review. Open Journal of Pathology, 11, 1-6. https://doi.org/10.4236/ojpathology.2021.1 11001

Received: September 3, 2020

Accepted: December 21, 2020

Published: December 24, 2020

Copyright $\odot 2021$ by author(s) and Scientific Research Publishing Inc. This work is licensed under the Creative Commons Attribution International License (CC BY 4.0).

http://creativecommons.org/licenses/by/4.0/

\begin{abstract}
Schistosomiasis is a chronic disease, and remains a major public health problem. It holds second place among parasitic endemics in the world. Schistosoma can infect various organs through the blood vessels. The genital form affects at least 16 million women in endemic areas, and the uterine cervix is the most common site. Two cases of cervical cancer associated with schistosomiasis of the cervix are presented. The aim of this study is to discuss the epidemiological, clinical and histopathological features. Both of the patients lived in Mahanjaga, aged respectively 57 and 43 years old. They complained of uterine bleeding disorder and presented cauliflower lesions with ulceration of the uterine cervix that extended to the vagina in one case. They were undergone cervical biopsies. The diagnosis was, in both cases, invasive, well-differentiated squamous cell carcinoma with cervical schistosomiasis.
\end{abstract}

\section{Keywords}

Cervical Cancer, Schistosomiasis, Schistosoma haematobium, Madagascar

\section{Introduction}

Schistosomiasis, also known as bilharzia, is a parasitic disease caused by trematode flukes of the genus, Schistosoma. Five species are pathogenic and cause human infection. Schistosoma haematobium is responsible for urinary and genital schistosomiasis. It is a major parasitic endemic and ranks second of parasitic disease, after malaria by the World Health Organization (WHO) [1].

Schistosoma can affect several organs through the human blood vessels. One 
of the main consequences is tissue infiltration of Schistosoma ova. It induces persistent chronic inflammation which is responsible for the production of a carcinogenic enzyme: beta-glucuronidase [1] [2]. The association of schistosomiasis and cancer of the cervix is little reported, at least in Madagascar.

Two cases of cervical cancer associated with schistosomiasis are presented. The aim of this study is to discuss the epidemiological, clinical and histopathological features.

\section{Observation}

Case No. 1

A 57-year-old Malagasy woman, lived in Mahanjaga (a region in the western part of Madagascar), Betsirebaka ethnic group. She had been postmenopausal for 4 years. She was examined because of uterine bleeding disorder. She presented a necrotic lesion with erosion in the uterine cervix, extending to the vagina and was undergone for cervical biopsy. Samples (four fragments) were firm; the diameter varies from 0.3 to $0.5 \mathrm{~cm}$. Histological examination revealed an invasive carcinomatous proliferation in a cervical mucosa. The cells presented a moderate cyto-nuclear atypia, organized in clusters, with squamous differentiation without keratinization. The stroma was fibrous with numerous calcified Schistosoma ova. The diagnosis was well-differentiated, invasive squamous cell carcinoma with cervical schistosomiasis (Figure 1). Praziquantel was given at 40 $\mathrm{mg} / \mathrm{kg}$ body weight. The patient was undergone for hysterectomy and radiation therapy.

Case No. 2

She was 43-year-old, lived in Mahanjaga (Sakalava ethnic group). She was undergone for a gynaecological examination at the hospital in the region because of a dysmenorrhea. The patient presented an ulceration of uterine cervix. Cervical biopsies were performed and the samples were sent to Antananarivo, at JRA University Hospital. There were multiple fragments, with $2.2 \times 1.6 \times 0.5 \mathrm{~cm}$

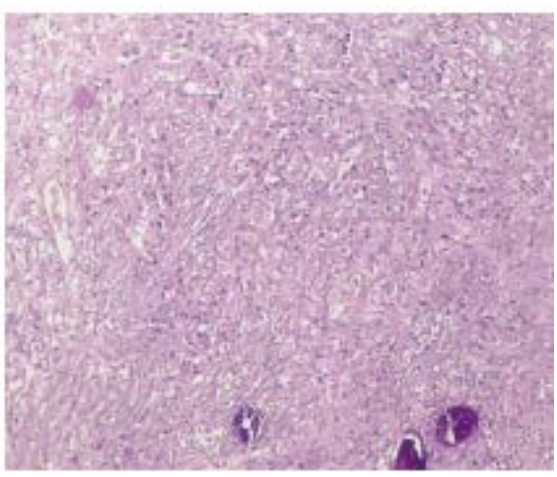

(a)

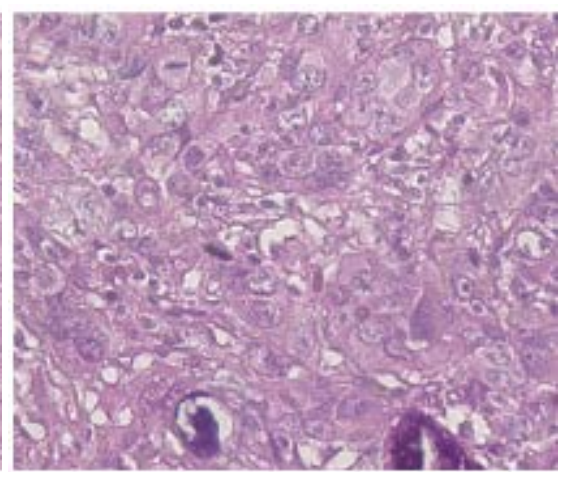

(b)

Figure 1. Uterine cervix. Well-differentiated, invasive squamous cell carcinoma with numerous calcified schistosome eggs (arrow). HE $\times 40$ (a) $\times 400$ (b). Source: Department of Pathology, Joseph Ravoahangy Andrianavalona University Hospital, Antananarivo, Madagascar. 
diameter in clusters. The histological features were an infiltrating tumor proliferation, with squamous differentiation and keratinization. Calcified schistosome eggs surrounded by inflammatory granulomas with multinucleated giant cells were found in the stroma. The diagnosis was a well-differentiated, invasive squamous cell carcinoma with schistosomiasis (Figure 2). Praziquantel was given at $40 \mathrm{mg} / \mathrm{kg}$ body weight and she was undergone for hysterectomy.

\section{Discussion}

Worldwide, bilharzia affects at least 200 million people, the equivalent of one among 30 people [3] [4] and $80 \%$ are in Africa [5]. Madagascar is one of the endemic African countries, it occurs especially in the western part [6]. Both of our patients lived in this coast of the island. Lesions are caused by host responses to dead or viable schistosomiasis eggs into different organs and lead for different forms of the pathology: urinary, genital, ... Concerning the genital schistosomiasis, it can affect the different part of the female genital tract, but uterine cervix is the most common site to harbor Schistosoma haematobium [7] [8].

Cervical schistosomiasis can be asymptomatic for a long time [9]. Concerning the symptomatic form, symptomatology is unspecific and the patients may present leucorrhoea, dyspareunia or dysmenorrhea. Clinical appearance may take one of three different forms: endocervical polypoid excrescences; indurated area with zones of ulceration or erosion; cauliflower mass which bleeds on touch, thus simulating cervical carcinoma. Ulceration is the most characteristic pathological finding [10]. Both of our patients presented dysmenorrhea with ulceration zones, and underwent a biopsy for histological examination.

The diagnosis of bilharzia was confirmed by the presence of schistosome granuloma or schistosome eggs. The lesions are located in the mucosa, the submucosa and sometimes in the muscularis mucosae [11]. Several cases of cervical schistosomiasis have been reported and some are associated with cancer. In Senegal, Abdou Magib Gaye et al. [12] reported 6 cases, which represent $33.3 \%$ of cervical schistosomiasis and $0.2 \%$ of all cases of cervical cancer. Malagasy studies

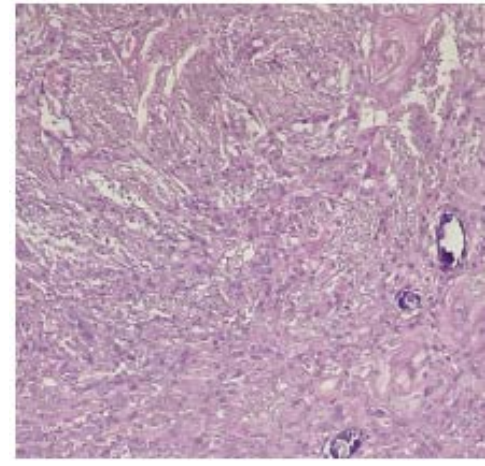

(a)

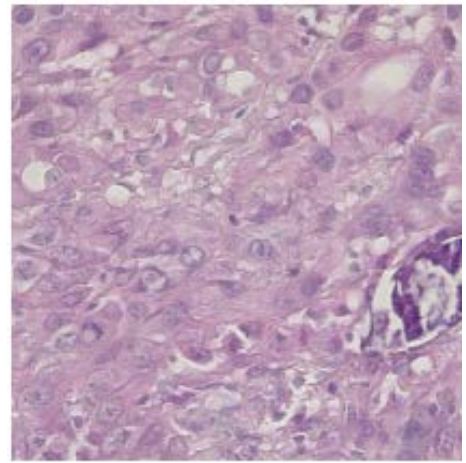

(b)

Figure 2. Well-differentiated, invasive squamous cell carcinoma with keratinization (arrow) with cervical schistosomiasis. HE $\times 40$ (a) $\times 400$ (b). Source: Department of Pathology, Joseph Ravoahangy Andrianavalona University Hospital, Antananarivo, Madagascar. 
by Rajaonarison JJC et al. [5] and Randrianasolo BS et al. [13] concerning genital schistosomiasis, have not reported any association with cervical cancer. However, HT Andrianjafitrimo et al. [14] identified one case of cancer developed on bilharzia among the 10 cases of cervical bilharzia. Squamous cell carcinoma is the most histological type in association with cervical schistosomiasis, as reported by Abdou Magib Gaye et al. [11] and HT Andrianjafitrimo et al. [14]. Our cases had the same histological type. G El Tabbakh et al. reported a case of adenocarcinoma with cervical schistosomiasis [10].

Regarding risk factors for developing cancer, urinary schistosomiasis is a known predisposing factor for bladder cancer. Human papillomavirus (HPV) infection is well established as a necessary cause of cervical cancer [15]. But the relationship of cervical schistosomiasis to cervical cancer is controversial. Szela et al. [14], for example, carried out a comparative study in 2 different regions, non-endemic and endemic for bilharzia. In the endemic area, $46 \%$ of patients presented cervical schistosomiasis, one of which with CIN2, and 33\% are HPV positive. In the non-endemic area, no morphological feature of schistosomiasis was observed after cervical biopsy, none of the patients presented a pre-cancerous lesion whereas $48 \%$ of them are HPV positive. They conclude that there is no causal relationship between cervical schistosomiasis and CIN or cervical cancer [16].

In the United States, on the other hand, KL Fachinan et al. [10] reported two cases, one of CIN3 and another of invasive cancer, with cervical schistosomiasis and no evidence of a high risk HPV of cervical cancer has been identified. They concluded that cervical schistosomiasis appears to be a possible risk factor for the development of CIN and cancer [11] [17]. Menye et al. [18] shared this same observation. The presence of Schistosoma ova lead to persistent chronic inflammation and ulceration of the cervix with formation of schistosoma granuloma [1] [2]. Cervicitis with ulceration can make or increase the virulence of a Human Papillomavirus infection. The majority of HPV infections are transient and not sufficient to induce carcinogenesis. Only persistent infections with high-risk HPV types will eventually result in progression towards invasive cervical cancer. Schistosomiasis may be a probable cofactor of uterine cervix cancer [12]. Kjetland et al. [4] found that the development of high-grade intraepithelial neoplasia was significantly associated with cervical schistosomiasis that has progressed for at least 5 years [4] [8].

Moubayed et al. [19] [20] found no association between cervical cancer and schistosomiasis. However, they observed that women with both schistosomiasis and cervical cancer are significantly younger than those affected only with cervical cancer. This could be matched with the hypothesis that bilharzia could increase the carcinogenic effect of HPV infection on the cervix. It can promote the persistence of HPV infection [19] [20].

\section{Conclusion}

The association of cervical cancer and schistosomiasis is still little reported in 
Madagascar. The evidence of the relationship between schistosomiasis and cervical cancer is not yet well defines. It is possible that chronic cervical infestation is a factor for a persistent HPV infection and subsequent development of cervical intraepithelial neoplasia. As Madagascar is an endemic country of schistosomiasis, through this study, it is important to keep in mind that patients with cervical schistosomiasis should be performed for regular screening for possible precancerous lesions.

\section{Conflicts of Interest}

The authors declare no conflicts of interest regarding the publication of this paper.

\section{References}

[1] Taylor, M. (2008) Global Trends in Schistosomiaisis Control. Bulletin of the World Health Organization, 86, 738. https://doi.org/10.2471/BLT.08.058669

[2] Parkin, D.M. (2006) The Global Health Burden of Infection-Associated Cancer in the Year 2002. International Journal of Cancer, 118, 3030-3044. https://doi.org/10.1002/ijc.21731

[3] Kjetland, E.F., Leutscher, P.D.C. and Ndhlovu, P.D. (2012) A Review of Female Genital Schistosomiasis. Trends in Parasitology, 28, 58-65. https://doi.org/10.1016/j.pt.2011.10.008

[4] Kjetland, E.F., Ndhlovu, P.D., Mduluza, T., Deschoolmeester, V., Midzi, N., Gomo, E., et al. (2010) The Effects of Genital Schistosoma haematobium on Human Papillomavirus and the Development of Cervical Neoplasia after Five Years in a Zimbabwean Population. European Journal of Gynaecological Oncology, 16, 169-173.

[5] Rajaonarison, J.J.C., Ratsiambakaina, D., Rakotomahenina, H., Ramiandrasoa, A.L., Maoulida, A.B.M., Andriamiandrisoa, A.B. and Randaoharison, P.G. (2017) La bilharziose génitale de la femme: A propos de cinq observations. Journal Malagasy de Gynécologie-Obstétrique, 1, 6-8.

[6] Gryseels, B., Polman, K., Clerinx, J. and Kestens, L. (2006) Human Schistosomiasis. The Lancet, 368, 1106-1118. https://doi.org/10.1016/S0140-6736(06)69440-3

[7] Gentilini, M. and Dufflo, B. (2000) Les maladies parasitaires: Les schistosomes. Médecine Tropicale, Aupelf.

[8] Christinet, V., Lazdins-Helds, J.K., Stothard, J.R. and Reinhard-Rupp, J. (2016) Female Genital Schistosomiasis (FGS): From Case Reports to a Call for Concerted Action against This Neglected Gynaecological Disease. International Journal for Parasitology, 46, 395-404. https://doi.org/10.1016/j.ijpara.2016.02.006

[9] Leutscher, P., Ravaoalimalala, V.E., Raharisolo, C., Ramarokoto, C.E., Rasendramino, M., Raobelison, A., et al. (1998) Clinical Findings in Female Genital Schistosomiasis in Madagascar. Tropical Medicine and International Health, 3, 327-332. https://doi.org/10.1046/j.1365-3156.1998.00230.x

[10] El Tabbakh, G. and Hamza, M.A. (1989) Carcinoma of the Uterine Cervix and Schistosomiasis. International Journal of Gynecology \& Obstetrics, 29, 263-268. https://doi.org/10.1016/0020-7292(89)90266-X

[11] Fachinan, K.L. (2010) Schistosomiase et pathologies du col utérin: A propos de 41 cas. 
[12] Gaye, A.M., Doh, K., Thiam, I., Bentefouet, L. and Woto-Gaye, G. (2016) Bilharziose et cancer: Une association fortuite ou une relation de cause à effet. Bulletin du Cancer, 103, 806-807. https://doi.org/10.1016/j.bulcan.2016.07.002

[13] Randrianasolo, B.S., Jourdan, P.M., Ravoniarimbinina, P., Ramarokoto, C.E., Rakotomanana, F., Ravaoalimalala, V.E., et al. (2015) Gynecological Manifestations, Histopathological Findings, and Schistosoma-Specific Polymerase Chain Reaction Results among Women with Schistosoma haematobium Infection: A Cross Sectional Study in Madagascar. The Journal of Infectious Diseases, 212, 275-284. https://doi.org/10.1093/infdis/jiv035

[14] Andrianjafitrimo, H.T., Ranaivomanana, V.F., Ravelomampitoniainarivony, T.M., Ramiandrasoa, L.A. and Randrianjafisamindrakotroka, N.S. (2019) Bilharziose du tractus génital étude bicentrique. Médecine et Santé Tropicale, 29, 306-309.

[15] Petry, K.U., Scholz, U., Hollwitz, B., Von Wasielewski, R. and Meijer, C.J.L.M. (2003) Human Papillomavirus, Coinfection with Schistosoma haematobium, and Cervical Neoplasia in Rural Tanzania. International Journal of Gynecological Cancer, 13, 505-509. https://doi.org/10.1136/ijgc-00009577-200307000-00015

[16] Szela, E., Bachicha, J., Miller, D., Till, M. and Wilson, J.B. (1993) Schistosomiasis and Cervical Cancer in Ghana. International Journal of Gynecology \& Obstetrics, 42, 127-130. https://doi.org/10.1016/0020-7292(93)90625-7

[17] North, M., Dubinchik, I., Hamid, A., Elderiny, S. and Sayegh, R. (2003) Association between Cervical Schistosomiasis and Cervical Cancer. A Report of 2 Cases. Journal of Reproductive Medicine, 48, 995-998.

[18] Menye, P.A., Serafino, X., Quenum, C. and Camara, M. (1965) Bilharziose et cancer du col utérin. Societe Medicale d'Afrique Noire, 3, 326-332.

[19] Moubayed, P., Lepere, J.F., Mwakyoma, H. and Neuvians, D. (1994) Carcinoma of the Uterine Cervix and Schistosomiasis. International Journal of Gynecology \& $\mathrm{Ob}$ stetrics, 45, 133-139. https://doi.org/10.1016/0020-7292(94)90120-1

[20] Moubayed, P., Ziehe, A., Peters, J., Mwakyoma, H. and Schmidt, D. (1995) Carcinoma of the Uterine Cervix Associated with Schistosomiasis and Induced by $\mathrm{Hu}$ man Papillomaviruses. International Journal of Gynecology \& Obstetrics, 49, 175-179. https://doi.org/10.1016/0020-7292(95)02332-7 